\title{
THE CLASSIFICATION OF Fe XVIII TO XXIV EMISSION LINES IN SOLAR FLARE SPECTRA
}

\author{
B. C. FAWCET'T \\ Astrophysics Research Unit, Science Research Council, Culham Laboratory, \\ Abingdon, Berks., England
}

This paper reports recent progress in the classification of the spectra of iron Xvill to XXIV. Emission lines due to these stages of ionisation were reported in the spectra of solar flares by Neupert et al. (1967) who pointed out that the $2 s^{2} 2 p^{n}-2 s^{2} 2 p^{n-1} 3 d$ configurations were mainly responsible. The present work verifies this and in addition gives individual line classifications of some of the strongest lines. Earlier studies of these transitions were reported by Fawcett (1965), Fawcett et al. (1967), and Feldman and Cohen $(1968,1970)$. Spectra of Fe XViII to XXIV due to $2 s^{2} 2 p^{n}-2 s 2 p^{n+1}$ transitions lie near $90 \AA$. Satisfactory solar and laboratory observations of these spectra are not yet available. The new classifications in these isoelectronic sequences are extended almost as far as iron and enable accurate extrapolations to iron. Isoelectronic spectra of both the forementioned transitions have been studied and the wavelengths tabulated (Fawcett, 1970, 1971a, b; Fawcett et al., 1971) for all the elements in the period between silicon and iron. The wavelength data enables the calculation of the $2 s^{2} 2 p^{n}$ energy levels and hence provides confirmation of the identity of solar forbidden lines in silicon, sulphur, argon and calcium. These energy levels are in close agreement with the theoretical calculations of Edlén reported at this Conference.

\section{References}

Fawcett, B. C.: 1965, Proc. Phys. Soc. 86, 1087.

Fawcett, B. C.: 1970, J. Phys. B Atom. Molec. Phys. 3, 1152.

Fawcett B. C.: 1971a, J. Phys. B Atom. Molec. Phys. 4, 981.

Fawcett, B. C.: 1971b, Astrophysics Unit Report ARU R2. Available from Her Majesty's Stationary Office.

Fawcett, B. C., Gabriel, A. H., and Saunders, P. A. H.: 1967, Proc. Phys. Soc. 90, 863.

Fawcett, B. C., Gabriel, A. H., and Paget, T. M.: 1971, J. Phys. B Atom. Molec. Phys. $4,986$.

Feldman, U., and Cohen, L.: 1968, Astrophys. J. 151, 55.

Feldman, U., and Cohen, L.: 1970, Astrophys. J. 160, 105.

Neupert, W. M., Gates, W., Swartz, M., and Young, R.: 1967, Astrophys. J. 149, 79.

\section{DISCUSSION}

R. C. Elton: I wish to point out some new results from M. Swartz, S. Kastmet, E. Rothe and W. Neupert (which have been accepted for publication) which include spectra from $\mathrm{Cr}, \mathrm{Mn}, \mathrm{Fe}, \mathrm{Co}, \mathrm{Ni}$ and $\mathrm{Cu}$ in the 8-18 $\AA$ region. Isoelectronic extrapolations are used in identifications.

B. C. Fawcett: The paper which you mention and say confirms that of Connerade et al. in their classifications of Fexviı, FexviII and Fexıx will probably have to be used with caution in interpreting the spectra of solar flares. The reason is that the spectra of FexVIr, FexVIII and FexIX contain a few strong lines and a lot of relatively weak ones. In the very highly ionised spectra of solar flares reported 
by Neupert the weak FexviI and Fexix lines are obscured by much more intense Fexx to xxIv lines which must be responsible for at least $95 \%$ of the observed intensities. Various workers have made the mistake of comparing the wavelengths of weak FexvII-Fexix lines with those of the Fexx to XxIV lines observed by Neupert and have made wrong identifications. The FexvII to XIX wavelengths can be usefully compared with the spectra of the quiet Sun.

$M$. Kuperus: How many stages of ionization, say of iron, do you observe at one moment?

B. C. Fawcett: The number of stages observed generally depends on the source. Vacuum sparks, for instance of the type used at Lund University, can emit all stages of ionization between FeI and FexviIr. Low inductance sparks such as the one built by Dr Feldman may reach Fexxv. The Culham theta-pinch in the Astrophysics Research Unit emits stages of ionization between Fevir and Fexvi with lower stages comparatively weak. As the appearance of lines belonging to a particular stage of ionization is time dependent: photomultipliers, or shutters can be used to isolate particular stages of ionization. This, overcomes the disadvantage of spark sources whose spectra is confused by spatial overlapping of stages of ionization. Unlike spark sources the parameters of the theta-pinch plasma can be determined by laser scattering. Provided technical difficulties such as the determination of the number density of the ions are overcome then useful absolute intensity measurements of these iron lines can be made. 